\title{
N-halamines from rice straw
}

2 Abd El-Shafey I. Ahmed ${ }^{*}$ Gabriel Cavalli ${ }^{\star}$ John N. Wardell ${ }^{\star}$ Michael E. Bushell

John N. Hay

4 A. E.-S. I. Ahmed (corresponding author)

5 Department of Chemistry, Faculty of Science, University of Zagazig, Zagazig, Egypt

$6 \quad$ A. E.-S. I. Ahmed $^{`}$ G. Cavalli` J. N. Hay

7 Chemical Sciences, FHMS, University of Surrey, Guildford, Surrey, UK

$8 \quad$ J. N. Wardell ${ }^{*}$ M. E. Bushell

9 Microbial Sciences, FHMS, University of Surrey, Guildford, Surrey, UK

10 e-mail: a.i.ahmed@surrey.ac.uk

11 Abstract The cellulosic part of rice straw was modified to develop N-halamine

12 derivatives for disinfection. The process involved cross-linking of the cellulosic material

13 with amino/amide/imide containing compounds; cyclic and acyclic. The structures of the

14 prepared materials were identified using FTIR and solid state ${ }^{13} \mathrm{CNMR}$. The modified

15 materials were halogenated to form N-halamines and the antimicrobial activity of each

16 evaluated against examples of Gram-positive (Staphylococcus aureus) and Gram-

17 negative bacteria (Escherichia coli) using a variety of methods; agar plate, blended agar,

18 stirred flask and in columns. One of the N-halamines achieved a $9 \log$ reduction against

19 both $E$. coli and S. aureus in 4 hours. In addition, no S. aureus growth was recorded on

20 agar plates blended with $0.5 \mathrm{~g}$ of this same material.

21 Keywords: Bioactive materials, Cellulose, N-halamine, Bacteria, Cross-linking. 


\section{Introduction}

2 The generation of straw waste constitutes a difficult environmental issue associated with

3 rice production. Despite some suggested uses to reduce the overall waste, such as paper

4 manufacturing, charcoal production, and conversion to animal food, this remains an issue

5 (Mansour et al., 2007; Suramaythangkoor and Gheewala 2010). As a result, most rice-

6 straw waste is burnt, producing significant air pollution associated with fume and smoke

7 generation; the obvious carbon footprint derived from this activity. In rice producing

8 countries, such as Egypt, this problem is evident each year during the rice production

9 season (Abou Zeid et al., 2008; Garas et al., 2008). Air pollution affects not only the

10 population's health but other sectors of the economy, such as tourism, and cultural

11 heritage (damage to buildings and artifacts). We herein propose the use of waste rice

12 cellulosic materials for water disinfection purposes; both as a means of dealing with the

13 large amounts of rice waste, as well as, tackling access to healthy sources of water for the

14 affected rural communities.

15 Cellulosic material from rice straw was extracted and cross-linked with

16 amino/amide/imide containing compounds; cyclic and acyclic (AAICC; C/A), such as

17 urea, barbituric acid and cynuric acid, followed by halogenation to form N-halamine

18 biocidal materials. This method can be applied to any agricultural waste or food remains

19 containing cellulosic material.

20 N-halamine polymers stabilize attached halogen moieties and deliver them to

21 microorganisms that approach the polymers (Ahmed et al., 2008a, b, 2009, 2010, 2011a

22 and b). They are usually prepared by loading heterocyclic rings that contain amide, imide

23 or amino function groups which can be halogenated to the polymer backbone (Ahmed et 
1 al., 2008a). When the bacterial cells come in contact or close association with the

2 polymer, the halide ion can be exchanged between the polymer and the cell (Ahmed et

3 al., 2009 and 2010). These polymers exchange halide ions with the cells by contact,

4 release, and may change the nature of medium around the cells (Ahmed et al., 2009 and

5 2010).

6 In the literature there are reports of trials to prepare biocidal polymers by loading

7 acyclic moieties to a polymer backbone that contains amide function groups, followed by

8 halogenation, to form N-halamine textiles (Liu and Sun, 2006). We have developed N-

9 halamine derived polymeric materials for biocidal applications (Ahmed et al., 2008a, b,

$102009,2010,2011 \mathrm{a}$ and $\mathrm{b}$ ) and now this expertise has been transferred to the halogenation

11 of cellulosic material.

12 In this work we have used both cyclic and acyclic moieties, example in Fig. 1, in 13 grafting to cellulose extracted from rice straw; to compare the reactivity of both of types.

14 In addition, two further factors were considered; the associated costs of each moiety and

15 their stabilization of the resulting halogen ion. The cross-linking agents, that would carry

16 the halogen, were attached using one-step chemical transformations. Moieties containing

17 more than two amino, amide or imide protons were selected for this job, example in Fig.

18 1. Two of the groups were used in the cross-linking process while the rest were left to

19 carry the halide ion, Fig. 1. The novel modified cross-linking process will be supported

20 by the presence of epichlorhydrin in a reaction through the cellulose hydroxyl groups as

21 reported in the literature (Zhou et al., 2007; Simkovic, 1999; Nada and Hassan, 2005).

22 The antimicrobial activity of the halogenated form of these products was

23 examined by challenge against bacteria to investigate the potential of such materials as 
1 disinfectants. This was achieved by different methods; such as agar plate (Ahmed et al.,

2 2008a), blended agar, a stirred flask and column methods (Ahmed et al., 2008b, 2009 and

3 2010). The stirred flask method was used to determine the effect of one of the prepared

4 materials on bacterial viability and growth (Ahmed et al., 2008b). The prepared materials

5 were also evaluated as potential disinfecting water filters using a column method,

6 (Ahmed et al., 2008b).

7 Experimental

8 Materials

9 Rice straw was supplied from a farm in Sharkia Governorate, a region in the east Nile

10 delta, Egypt. Sodium hydroxide, sodium hypochlorite $(10 \% \mathrm{w} / \mathrm{v})$ and cyanuric acid were

11 supplied by Fisher Chemicals, UK. Epichlorohydrin, barbituric acid, semicarbazide,

12 chloroacetamide and urea were supplied by Sigma-Aldrich Chemicals, UK.

\section{Growth and maintenance of stock cultures}

14 Staphylococcus aureus and Escherichia coli were obtained from the University of Surrey

15 culture collection. Primary cultures were maintained on nutrient agar slopes stored at $4^{\circ} \mathrm{C}$.

16 Experimental stocks of the bacteria were prepared by making subcultures of the primary

17 culture on nutrient agar plates. Subcultures were grown at $37^{\circ} \mathrm{C}$ for 24 hours and then

18 stored at $4^{\circ} \mathrm{C}$.

19 


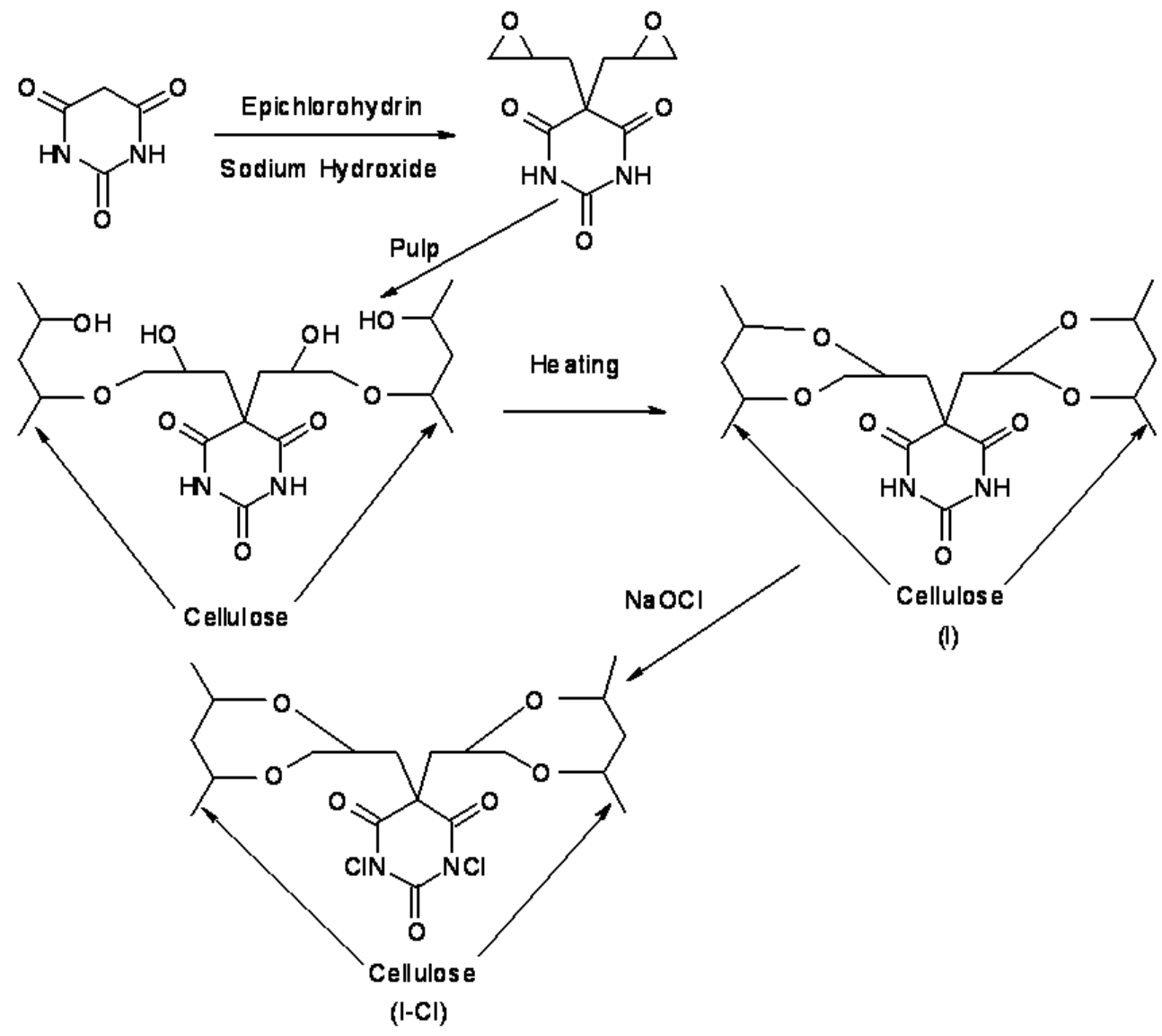

2 Fig. 1 Cross-linking with Barbituric acid

4 Cellulose extraction (pulping and bleaching)

Dry rice-straw $(10 \mathrm{~g})$ was ground and soaked in sodium hydroxide solution

$6(17.5 \%, 100 \mathrm{ml})$ in a $250 \mathrm{ml}$ round bottom flask. The suspension was refluxed for $1 \mathrm{hr}$ and

7 the resulting material filtered, washed with distilled water to neutralization and dried at

$8100^{\circ} \mathrm{C}$ for $24 \mathrm{hrs}$. The cellulosic material was bleached using sodium hypochlorite (single

9 stage bleaching) (Helmy and Abou-State, 1993). Chemical analysis of raw material

10 showed that the ratios of $\alpha$-cellulose, hemicellulose and lignin were $37.2,24.7$ and $16.2 \%$

11 respectively while after pulping they were $89.3,8.6$ and $0.8 \%$ respectively. After 
1 bleaching the ratios of $\alpha$-cellulose and hemicellulose were 90.3 and $0.6 \%$ respectively

2 while the degree of polymerization was 762.6 and brightness $87.3 \%$.

3 General method for cross-linking with Barbituric acid, Cyanuric acid, urea and 4 semicarbazide

5 Amino/amide/imide containing compound was dissolved in sodium hydroxide solution

$6 \quad(100 \mathrm{ml}, 0.7 \% \mathrm{w} / \mathrm{v})$. Epichlorhydrin $(1.7 \mathrm{~g})$ was added and the reaction heated at $60^{\circ} \mathrm{C}$ for

$730 \mathrm{~min}$. The cellulosic material $(1 \mathrm{~g})$ was added and the reaction continued for an extra 2

8 hours. The resulting grafted product was filtered, washed with distilled water and dried at

$995^{\circ} \mathrm{C}$ for 1 hour; then cured at $140^{\circ} \mathrm{C}$ for another 1 hour to increase the cross-linking

10 possibilities, Fig. 1. The amounts of AAICC; C/A (barbituric acid, cyanuric acid, urea

11 and semicarbazide) were $1.2,1.9,0.6$ and 0.7 respectively to produce samples I, II, III

12 and IV respectively. FTIR and solid state ${ }^{13} \mathrm{CNMR}$ of the produced samples are given in

13 Table 1.

\section{Cross-linking with chloroacetamide}

15 Dried cellulosic material $(1 \mathrm{~g})$ was suspended in distilled water $(100 \mathrm{ml})$ and sodium 16 hydroxide $(0.7 \mathrm{~g})$ was added. The solution was cooled, chloroactamide $(0.9 \mathrm{~g})$ added and 17 the reaction stirred at $40^{\circ} \mathrm{C}$ for $1 \mathrm{hr}$. Epichlorohydrin $(0.9 \mathrm{~g})$ was added and the stirring 18 continued for an extra $1 \mathrm{hr}$. The temperature was then raised gradually to $60^{\circ} \mathrm{C}$ and then to $1980^{\circ} \mathrm{C}$ over $2 \mathrm{hrs}$. The resulting product was filtered, washed with distilled water, dried at $2095^{\circ} \mathrm{C}$ for $1 \mathrm{hr}$ and then cured for an extra 1 hour at $145{ }^{\circ} \mathrm{C}$. FTIR and solid state ${ }^{13} \mathrm{C}$ NMR 21 analysis for the product are in Table 1. 
2 Table 1 FTIR and Solid state ${ }^{13} \mathrm{C}$ NMR analysis of different cross-linked pulps.

\begin{tabular}{|l|l|l|}
\hline Sample & FTIR, $v\left(\mathrm{~cm}^{-1}\right)$ & Solid state ${ }^{13} \mathrm{C}$ NMR \\
\hline I & 1666,1697 and 3124 & $\begin{array}{l}32,41,44,62,75,84,88,105,107,117, \\
168 \text { and } 173\end{array}$ \\
\hline II & 1670 (broad band) and 3126 & $31,42,47,62,75,84,87,105,107,179$ \\
& & and 182
\end{tabular}

3 Where: I = pulp cross-linked with barbituric acid, II = pulp cross-linked with cynuric

4 acid, III = pulp cross-linked with urea, IV = pulp cross-linked with semicarbazide and V

$5=$ pulp cross-linked with chloroactamide.

6

7 Chlorination

8 Prepared samples of different products (I-V) were halogenated by soaking $1 \mathrm{~g}$ of each

9 sample in sodium hypochlorite $(10 \mathrm{ml}, 10 \%)$ for $1 \mathrm{hr}$ at ambient temperature. The

10 resulting samples were filtered, washed copiously with distilled water and dried at $40^{\circ} \mathrm{C}$

11 overnight. The halogen content was determined using iodometric titration, Table 2 
1 (Ahmed et al., 2008a; Chen and Sun 2006), and the halogenation process was followed by

2 FTIR, Table 2 (Ahmed wt al., 2008a; El-Masry et al., 2004a and b).

4 Table 2 Halogen content and FTIR characterization of each chlorinated sample

\begin{tabular}{|c|c|c|}
\hline Sample number & Halogen content $(\mathrm{ppm})$ & $\begin{array}{c}v_{\max }\left(\mathrm{cm}^{-1}\right) \text { of N-Cl in each } \\
\text { halogenated material }\end{array}$ \\
\hline I-Cl & $112 \pm 10$ & 805 \\
\hline II-Cl & $123 \pm 14$ & 775 \\
\hline III-Cl & $164 \pm 12$ & 760 \\
\hline IV-Cl & $56 \pm 11$ & 763 \\
\hline V-Cl & $60 \pm 9$ & \\
\hline
\end{tabular}

5

6 Biological activity

\section{Agar plate method}

8 Nutrient agar (Oxoid) was prepared $(250 \mathrm{ml})$, held molten at $50^{\circ} \mathrm{C}$ and $1.0 \mathrm{ml}$ of a $17 \mathrm{~h}$

9 nutrient broth culture of either S. aureus or E. coli was added. The seeded agar was

10 poured into Petri dishes; 3 dishes for each sample (triplicates) per bacterium type (E. coli

11 or S. aureus). Wells $(5 \mathrm{~mm})$ were cut into the agar in the middle of each dish. Small

12 amounts of each sample $(0.05 \mathrm{~g})$ were placed in the corresponding well. The dishes were

13 incubated for $24 \mathrm{hr}$ at $37^{\circ} \mathrm{C}$ and the inhibition zones around the sample were recorded,

14 Table 3 (Ahmed et al., 2008a; El-Masry et al., 2004a and b).

15

16 


\section{Blended agar method}

2 Molten nutrient agar was cooled to around $40^{\circ} \mathrm{C}$ and blended (15 ml each) with different

3 amounts of III-Cl; $0.0,0.25,0.5,1.0,1.5$ and $2 \mathrm{~g}$ before pouring in plates. Bacterial

4 suspensions of E. coli and S. aureus were prepared by inoculating $10 \mathrm{ml}$ nutrient broth

5 with a single colony and incubating for 17 hours at $37^{\circ} \mathrm{C}$. The viability of each bacterium

6 was determined on the blended plates using the 'Miles and Misra' method (Miles and

7 Misra, 1938). Two controls were applied; counting on non-blended agar plates and agar

8 plates blended with the non-halogenated form of the material (III), Figs 2 and 3.

9

10 Table 3 Inhibition zones diameters $(\mathrm{mm})$ around different grafted samples on agar dishes

11 containing Gram-positive or Gram-negative bacteria.

\begin{tabular}{|c|c|c|}
\hline Sample number & E. coli & S. aureus \\
\hline I-Cl & $6 \pm 0$ & $9 \pm 1$ \\
\hline II-Cl & $6 \pm 1$ & $8 \pm 1$ \\
\hline III-Cl & $10 \pm 2$ & $12 \pm 0$ \\
\hline IV-Cl & ND & ND \\
\hline V-Cl & ND & ND \\
\hline
\end{tabular}

12

13

14

15

16

17 
1 Fig. 2 Counts on agar blended with III-Cl compared to counts on normal agar and agar 2 without any cells.

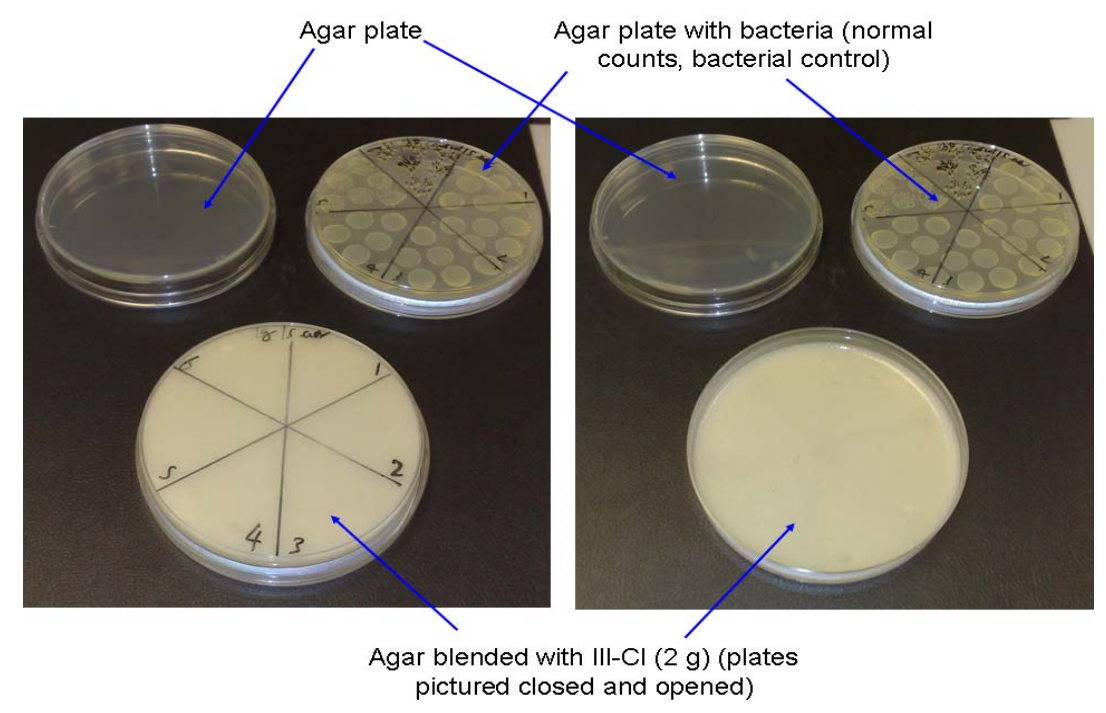


1 Fig. 3 Effect of blended agar with III-Cl on the viability of E. coli (a) and S.aureus (b).

2 Where $\mathrm{T}=$ plates blended with III-Cl, $\mathrm{PC}=$ III (non-halogenated material as a control)

3 and $\mathrm{BC}=$ bacterial control (no material). Error bars have been removed as the error is too

$4 \quad$ small to show on a log scale.

5

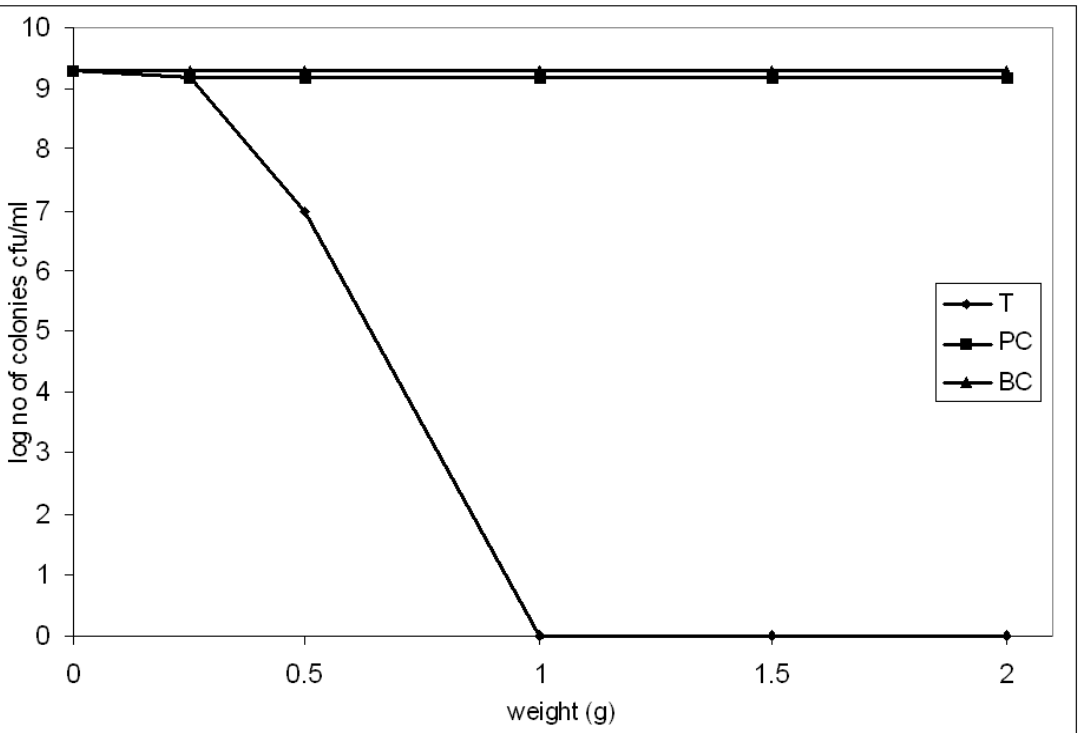

(a)

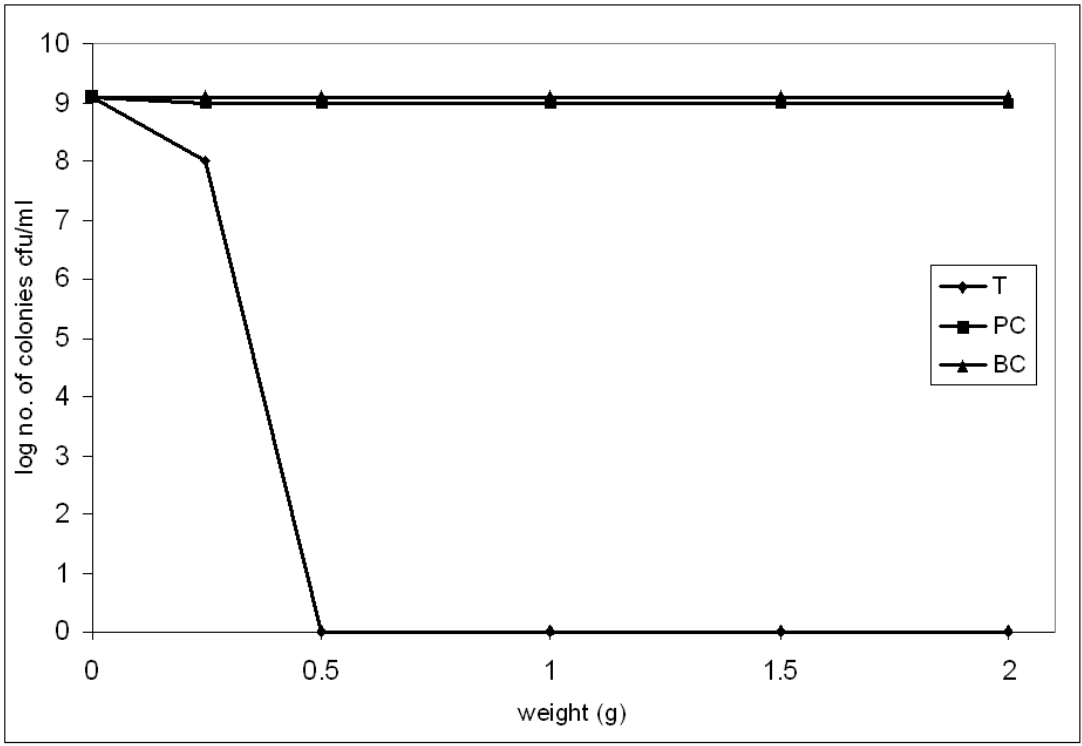

(b) 


\section{$1 \quad$ Stirred flask method}

2 A culture of $E$. coli was prepared by inoculating one bacterial colony into $20 \mathrm{ml}$ of

3 nutrient broth in a Universal bottle and incubating for $17 \mathrm{hr}$ at $37^{\circ} \mathrm{C}$. From the bacterial

4 suspension, $0.1 \mathrm{ml}$ was transferred to a $20 \mathrm{ml}$ Universal bottle containing $10 \mathrm{ml}$ of fresh

5 medium. Six Universals were prepared; three used in testing the effect of the halogenated

6 material on bacterial growth and the other three to test the effect on bacterial viability.

7 To study the effect on E. coli growth rate, $0.5 \mathrm{~g}$ of the halogenated material (III-

$8 \mathrm{Cl}$ ) was added to the first bottle of broth while $0.5 \mathrm{~g}$ of the control material (non-

9 halogenated, III) was added to the second bottle, and the third was left as a bacterial

10 control without any material. The three bottles were stirred at $37^{\circ} \mathrm{C}$ and sampled at timed

11 intervals for viable count, employing the 'Miles and Misra' technique, Fig. 4 (Miles and

12 Misra, 1938)

13 To investigate the effect of III-Cl on E. coli viability, the other three bottles,

14 inoculated as above, were incubated for $17 \mathrm{hr}$ at $37^{\circ} \mathrm{C}$, and the number of bacteria

15 determined by viable count. At this time $0.5 \mathrm{~g}$ of III-Cl was added to one bottle; $0.5 \mathrm{~g}$ of

16 the control material (non-halogenated, III) was added to the second, and the third vessel

17 was left as a bacterial control. The three bottles were stirred at ambient temperature, and

18 samples from each culture taken for viable count at regular time intervals, as previously,

19 Fig 5. The procedure was repeated to test the effect of III-Cl on a Gram-positive

20 bacterium (S. aureus) (Ahmed et al., 2008b and 2009). 
1 Fig. 4 Effect of III-Cl on the growth rate of E. coli (a) and S. aureus (b). Where T = 2 plates blended with III-Cl, PC = III (non-halogenated material as a control) and $\mathrm{BC}=$ 3 bacterial control (no material). Error bars have been removed as the error is too small to 4 show on a log scale.

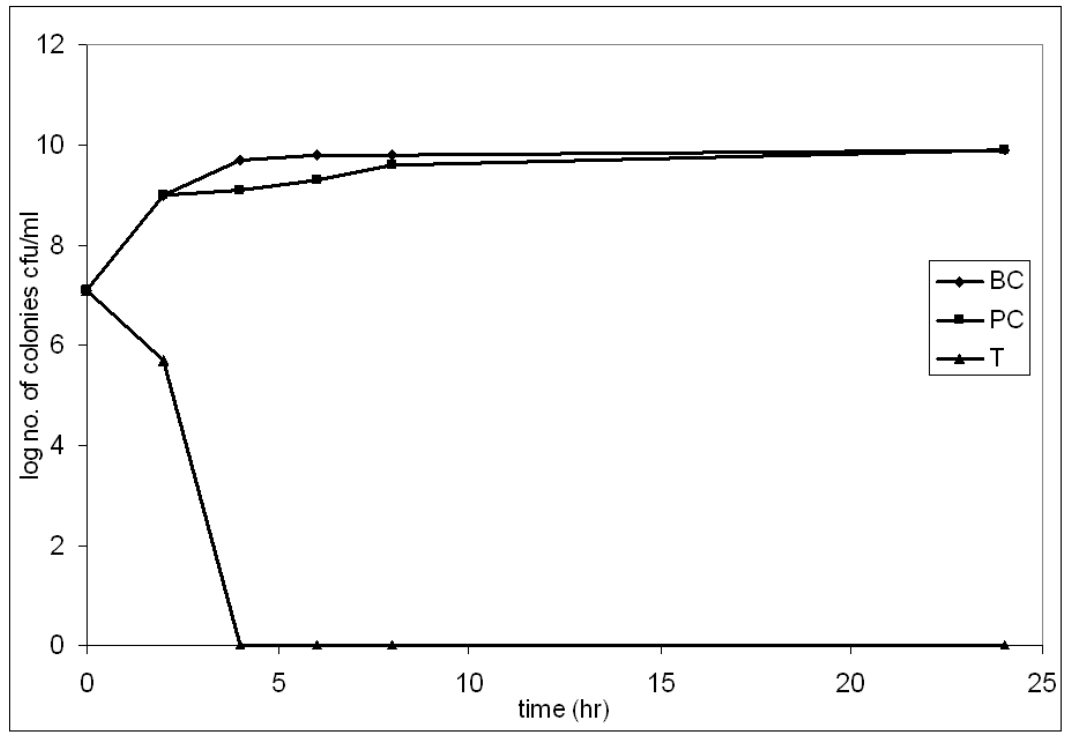

6

(a)

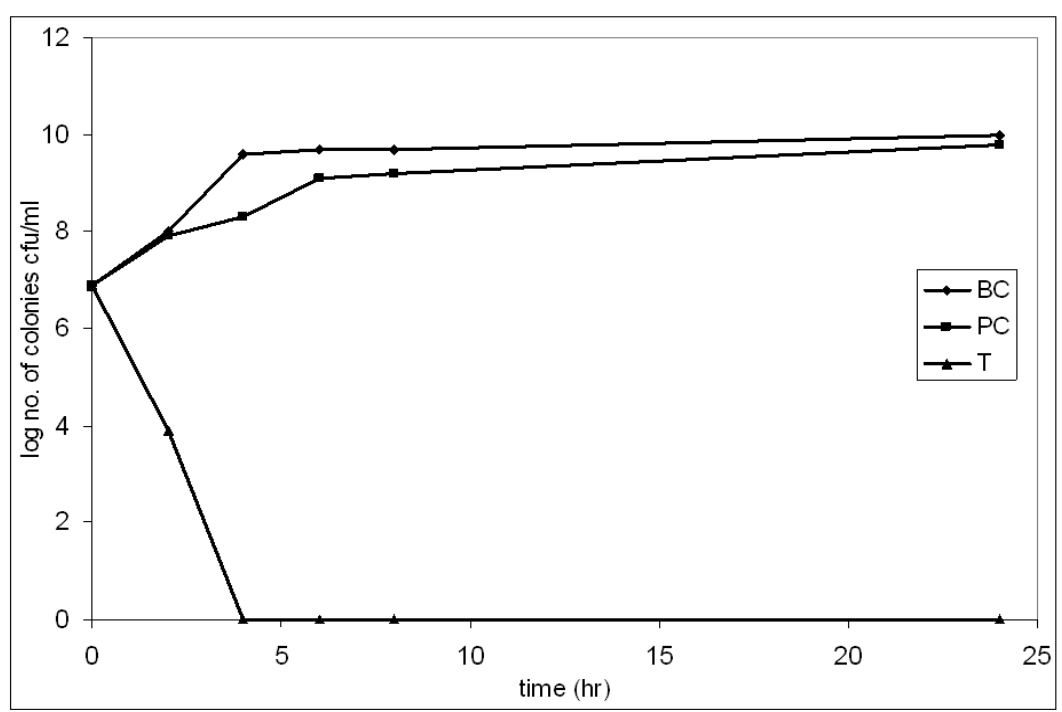

(b) 
1 Fig. 5 Effect of III-Cl on the viability of E. coli (a) and S. aureus (b). Where T = III-Cl,

$2 \quad \mathrm{PC}=\mathrm{III}$ (non-halogenated material as a control) and $\mathrm{BC}=$ bacterial control (no material).

3 Error bars have been removed as previously.

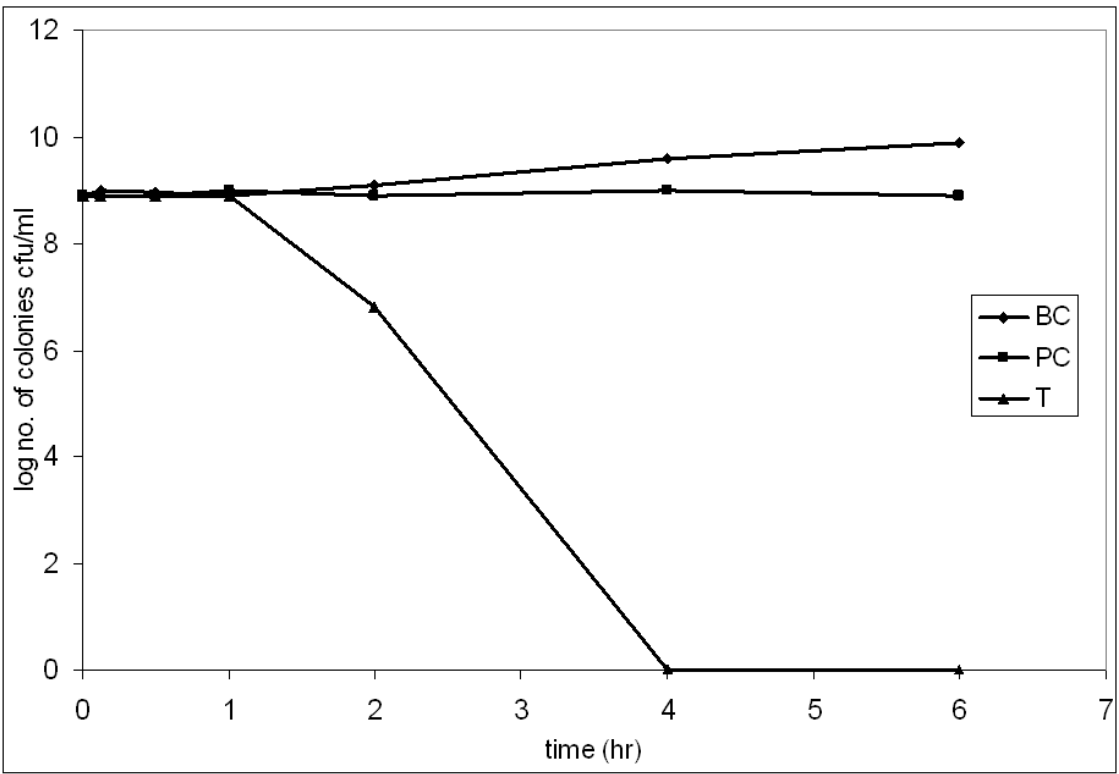

(a)

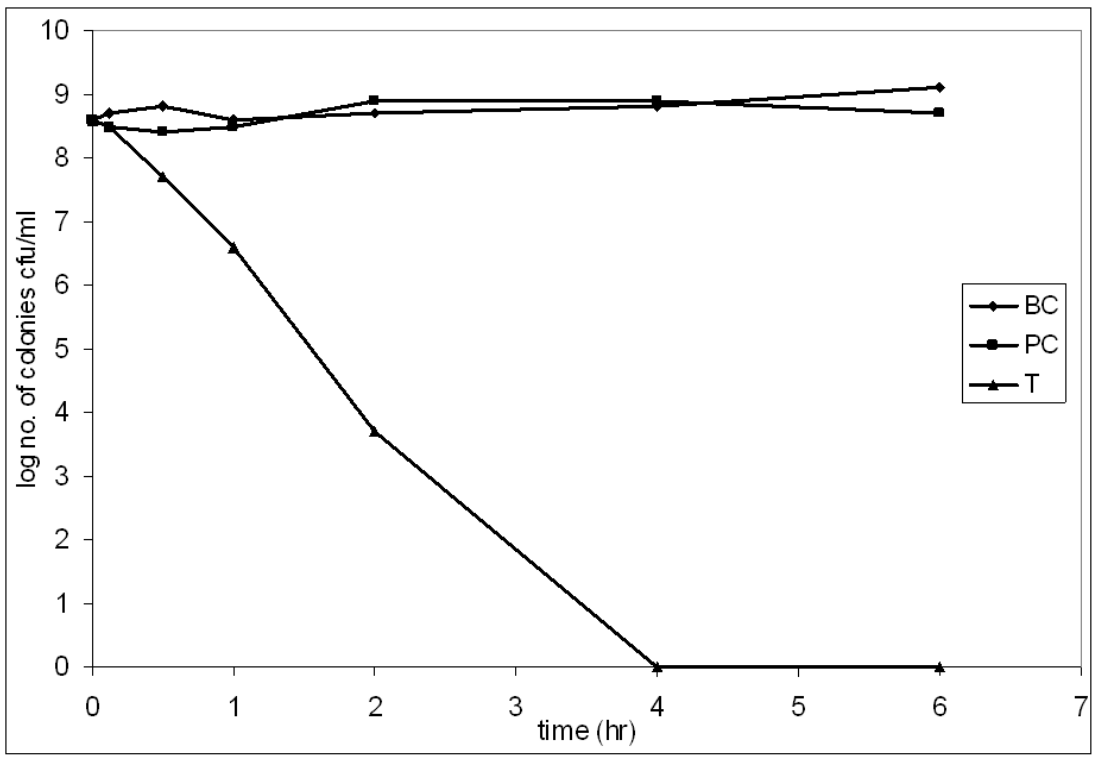

(b) 


\section{Column method}

2 Two glass tubes (10 cm length X $2.5 \mathrm{~cm}$ diameter) were loaded with III-Cl, $5.0 \mathrm{~g}$ each

3 (columns $\mathrm{C} 1$ and $\mathrm{C} 2$ ), while two similar columns were filled with III to be used as

4 controls (columns C3 and C4). Bacterial suspensions, either E. coli or S. aureus, were

5 prepared by inoculating $100 \mathrm{ml}$ of liquid medium followed by incubation for 17 hours at

$637^{\circ} \mathrm{C}$. E. coli suspension (concentration up to $2.4 \mathrm{X} 10^{7} \mathrm{cfu} / \mathrm{ml}$ ) was passed through

7 columns $\mathrm{C} 1$ and $\mathrm{C} 3(50 \mathrm{ml}$ each) and the output from the column recycled through it

8 again up to 10 times (recycling the same suspension through the same column). Before

9 recycling, $0.1 \mathrm{ml}$ from the passed liquid was sampled for viable count. The same protocol

10 was followed for S. aureus (concentration up to $1.3 \times 10^{7} \mathrm{cfu} / \mathrm{ml}$ ) using columns $\mathrm{C} 2$ and

11 C4 (Ahmed et al., 2008b).

12 The same method was followed to identify the useful lifetime of III-Cl in water

13 filters. In this case the above experiment was repeated up to 10 times (runs) and in each

14 run a fresh bacterial suspension with concentrations up to $10^{5} \mathrm{cfu} / \mathrm{ml}$ of $E$. coli was used.

15 In addition, each run includes 10 recycling times for the same suspension before

16 changing to the next run using a fresh suspension. Viable counts were performed at the

17 end of each run, example in Figure 6 (Ahmed et al., 2011b). At the end of the 10 runs,

18 and to investigate the regeneration possibilities of the column, the column was washed

19 copiously with sodium hypochlorite (10\%) followed by washing with distilled water. The

20 column was then closed, filled with sodium hypochlorite and left for 6 hours followed by

21 washing copiously with distilled water. The lifetime determination experiment was

22 repeated, as described above, up to 3 times (Ahmed et al., 2011b). 
1 Fig. 6 Different runs of $E$. coli through III-Cl column. Where $\mathrm{T}=\mathrm{III}-\mathrm{Cl}, \mathrm{PC}=\mathrm{III}$ (non2 halogenated material as a control). Error bars have been omitted as the error is too small 3 to show on a log scale.

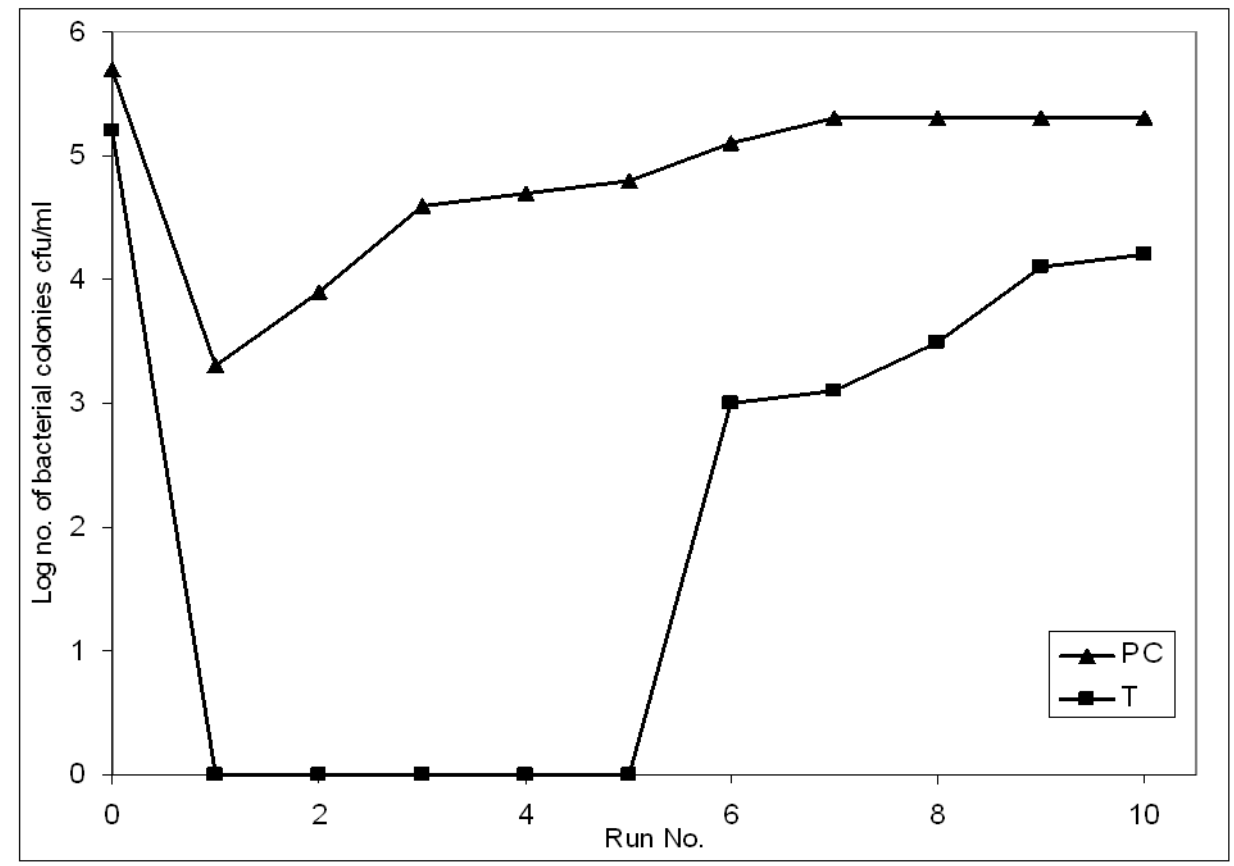

4

\section{$6 \quad$ Results and discussion}

7 Burning rice straw results in many health problems to the people who live in those 8 countries where rice is a major crop such as Egypt. Many applications (such as 9 production of paper, animal food, fertilizers and bio-fuel) have been suggested as uses for

10 such waste but the amount of straw produced remains too large (Navaee-Ardeh et al., 11 2004; Prasad et al., 1998; Sallam et al., 2007; Toor and Beri, 1991; Chou et al., 2009).

12 In our trials to produce low cost disinfectants, mainly for water treatment (Ahmed 13 et al., 2011b), we have found that rice straw waste can be a good source for cellulose that 14 can be modified to produce polymers with antimicrobial properties. Their commercial 
1 value starts from the fact that rice straw is currently freely available from farming

2 communities. In addition, most of the rice producing countries, especially in the third

3 world, have problems with inadequate supplies of clean drinking water. Therefore,

4 converting rice straw into a product with potential for use in water purification systems

5 results in an especially suitable way to address the problem of rice straw waste; thereby

6 reducing air pollution and providing a means of disinfecting drinking water in affected

7 communities.

8 As a result of this idea, cellulosic material was extracted from rice straw and

9 modified as N-halamine polymeric materials. The cellulose was extracted using sodium

10 hydroxide for one hour followed by bleaching using sodium hypochlorite. The resulting

11 material was cross-linked with AAICC; C/A that contained more than 2 amide or imide

12 function groups. Two of these function groups were used to achieve cross-linking to

13 cellulose in the presence of epichlorohydrin while the rest of the function groups were

14 left for halogenation. Compounds with an active methylene group such as barbituric acid

15 can be used to achieve cross-linking in a similar manner to the amide or imide groups.

16 At the same time, the process was performed using cyclic and acyclic compounds

17 to compare reactivity and production costs. Other factors, such as halogen stability were

18 also taken into consideration, as cyclic structures usually stabilize the halide ions attached

19 to it more than those of acyclic (Sun et al., 1996). Cynuric acid and barbituric acid, that

20 contain more than two amide/imide groups, were used as examples for the cyclic

21 compounds. Barbituric acid has an active methylene group with 2 hydrogens which can

22 facilitate cross-linking leaving the other 2 imide groups free for halogenation, Fig. 1.

23 Cynuric acid has 3 imide groups; two of them can perform the cross-linking leaving the 
1 third for halogenation. Cross-linking was performed usually in the presence of

2 epichlorhydrin; acting as a connector between the rings and the cellulose hydroxyl

3 groups.

$4 \quad$ FTIR and solid state ${ }^{13} \mathrm{C}$ NMR were used to investigate the success of the grafting

5 process, Table 1. From the FTIR data it was noticed that for all samples the NH amide or

6 imide band appears in the region $3100-3200 \mathrm{~cm}^{-1}$, while the $\mathrm{C}=\mathrm{O}$ bands usually appear in

7 the region from $1600-1700 \mathrm{~cm}^{-1}$. Solid state ${ }^{13} \mathrm{CNMR}$ showed that the cellulosic ring

8 carbons usually appear in the region from 60-110 ppm while the carbons of the

9 epichlorhydrin part appear in the region 30-55 ppm, Table 1 . In addition, the carbonyl

10 carbons usually appear in the region form 160-180 ppm.

11 All prepared materials and the corresponding N-halamine polymeric material

12 reacted with halide, Table 2 . It can be seen from Table 2 that the lowest charged material 13 with halogen was the pulp cross-linked with semicarbazide (IV) and with

14 chloroacetamide (V). We believe that this is because both of them have free amide (not

15 sharing in the cross-linking process) that may be broken during halogenation or curing. In

16 the case of chloroacetamide (V), epichlorohydrin addition was performed while the

17 cellulosic material was in the reaction container. This may affect the reaction because

18 there is a possibility that epichlorhydrin may perform cross-linking to the cellulose itself

19 without including the amide of chloroacetamide. This may have resulted in the presence

20 of free amide in compound (V) similar to that of (IV) which can be decomposed during

21 the halogenation, resulting in low halogen load and low biological activity. Currently we

22 are exploring connecting epichlorohydrin to chloroacetamide before reaction with

23 cellulosic material. This has affected the antimicrobial activity of compounds IV and V, 
1 as can be seen from the agar plate method to determine the antimicrobial activity, Table

2 3. All prepared materials showed antimicrobial activity against both Gram-positive and

3 Gram-negative bacteria except the materials cross-linked with chloroacetamide and

4 semicarbazide, Table 3. From Table 3 it can be seen that cross-linked material III has the

5 highest biological power, as it was carrying the highest chlorine content, Table 2; acyclic

6 amides can release halogen more readily than cyclic amides. Cyclic amides (as in I and

7 II) can stabilize the halogen more than acyclic amides. Moreover, connecting AAICC;

$8 \mathrm{C} / \mathrm{A}$ to cellulose through a carbon chain may help in stabilizing the halogen attached to

9 the compound due to the electron donating action of the methyl groups.

10 Further investigations were performed to determine the antimicrobial activity of 11 one of the prepared materials; III-Cl. This particular compound was selected due to its

12 high antimicrobial power in the agar plate experiment and also due to its expected low 13 production costs.

14 III-Cl was blended with nutrient agar before pouring as plates. The blending was 15 achieved with different amounts $0.0,0.25,0.5,1.0,1.5$ and $2 \mathrm{~g}$ per $15 \mathrm{ml}$ nutrient agar.

16 Bacterial counting using the 'Miles and Misra' method was performed on the surface of

17 the blended agar, Fig. 2. From Fig. 3, it can be seen, as expected, that increasing the 18 amount of III-Cl increased the antimicrobial action. One gram per $15 \mathrm{ml}$ nutrient agar was

19 enough to inhibit the growth of E. coli, Fig. 3a, while $0.5 \mathrm{~g} / 15 \mathrm{ml}$ nutrient agar achieved

20 the same goal for S. aureus, Fig. 3b. These results are encouraging and indicate that there

21 may be other applications for this product - blended in paints and surface coatings to 22 confer antimicrobial properties. 
Figs $5 \mathrm{a}$ and $5 \mathrm{~b}$ shows the effect of III-Cl on the viability of grown cultures of $E$.

2 coli and S. aureus respectively. III-Cl achieved a 9 log reduction for both types of

3 bacteria in 4 hours. At the same time no growth from either was detected in the presence

4 of III-Cl, Figs $4 \mathrm{a}$ and $4 \mathrm{~b}$.

A column method was used to show the ability of using such material in one of its

6 suggested applications; water filters. Bacterial suspensions (either E. coli or S. aureus)

7 were perfused through a column contains III-Cl and the outlet was recycled for up to 10

8 times through the same column. Viable counts after each perfusion through the column

9 indicated no detection. These results show that the column succeeded in disinfecting

10 bacterial suspensions with concentrations up to $10^{7} \mathrm{cfu} / \mathrm{ml}$ for both E. coli and S. aureus.

11 The same method was repeated for several runs (10 runs) to indicate the useful lifetime of

12 the column. The column stayed active for more than 5 runs, Figure 6, indicating that it

13 must be reloaded with halogen at this stage to be regenerated. To study the regeneration

14 possibilities the column was charged with halogen after the end of its lifetime and the

15 experiment of identifying the lifetime was repeated 3 times. It was found that the

16 regeneration process was successful and the column was regenerated successfully without

17 significant loss in its antibacterial action during those 3 repeats.

18 The above results showed that preparation of cross-linked materials was

19 successful and some of them have antimicrobial activity. Moreover, demonstrating that

20 the material has antimicrobial action, using agar plate and stirred flask methods, before

21 testing the material in columns indicated that the material is bactericidal; the effect in

22 columns is not due to a filtration effect only. Connecting AAICC; C/A to cellulose

23 through a carbon chain may aid stabilizing the halogen attached to the amide or imide 
1 groups. Moreover, stability of halogen attached to cyclic moieties is greater than that to

2 acyclic. However, acyclic moieties can be charged with more halogen and subsequently

3 release it more readily than cyclic ones. The compounds with free amide groups have a

4 low halogen content and consequently low biological activity.

5 Considering the economics of the processes, despite the evidence that cyanuric

6 and barbituric acids confer greater stability on the halogen, employing urea as the cross-

7 linker is more cost effective. Cyanuric acid can be used in the second stage as it could be

8 prepared from urea (El-Masry et al., 2004b). For future development of these materials

9 for field use, equilibrium has to be struck between stability and cost.

10 The above results encourage the development of such materials for a wide range

11 of applications where disinfection is important; such as surface coats and in water filters.

12 The environment is served in two important aspects: by reducing microbial growth and

13 contamination of water systems and by reducing the amount of atmospheric pollution due

14 to the current practice of burning-off rice-straw in the fields.

\section{Conclusion}

16 Novel N-halamine cellulosic materials were prepared and their structure elucidated using

17 FTIR and solid state ${ }^{13}$ CNMR. Some of the prepared materials achieved good

18 antimicrobial action in an agar plate method. Further antimicrobial investigations were

19 followed for one of the prepared materials (III-Cl). This compound succeeded in

20 inhibiting bacterial growth when both blended into agar and also in a stirred flask

21 method; achieving a $9 \log$ reduction in viable bacterial count in 4 hours. III-Cl was used

22 successfully in columns as model water filters and its functional lifetime and regeneration

23 possibilities determined. 


\section{Acknowledgments}

2 This project is funded by EPSRC and University of Surrey (Surrey Water Research

3 Group, UK.

4 References:

5 Abou Zeid AA, El-Fouly MZ, El-Zawahry YA, El-Mongy TM, Abd El-Aziz AB (2008)

6 Bioconversion of Rice Straw Xylose to Xylitol by a Local Strain of Candida $7 \quad$ Tropicalis. J Appl Sci Res 4:975-986.

8 Ahmed AEI, Hay JN, Bushell ME, Wardell JN, Cavalli G (2008a) Biocidal polymers (I):

9 Preparation and biological activity of some novel biocidal polymers based on uramil 10 and its azo-dyes. React Funct Polym 68:248-260.

11 Ahmed AEI, Hay JN, Bushell ME, Wardell JN, Cavalli G (2008b) Biocidal polymers (II): 12 Determination of biological activity of novel N-halamine biocidal polymers and 13 evaluation for use in water filters. React Funct Polym 68:1448-1458.

14 Ahmed AEI, Hay JN, Bushell ME, Wardell JN, Cavalli G (2009) Optimizing 15 Halogenation Conditions of N-Halamine Polymers and Investigating Mode of 16 Bactericidal Action. J Appl Polym Sci 113:2404-2412.

17 Ahmed AEI, Hay JN, Bushell ME, Wardell JN, Cavalli G (2010) Macroscopic N18 Halamine Biocidal Polymeric Beads. J Appl Polym Sci 116:2396-2408.

19 Ahmed AEI, Wardell JN, Thumser AE, Avignone-Rossa CA, Cavalli G, Hay JN, Bushell 20 ME (2011a) Metabolomic Profiling can Differentiate between Bactericidal Effects of 21 Free and Polymer Bound Halogen. J Appl Polym Sci 119:709-718. 
1 Ahmed AEI, Cavalli G, Bushell ME, Wardell JN, Pedley S, Charles K, Hay JN (2011b)

2 New approach to produce water free of bacteria, viruses, and halogens in a recyclable 3 system. Appl Environ Microbio 77:847-853.

4 Chen Z, Sun Y (2006) N-Halamine-Based Antimicrobial Additives for Polymers: 5 Preparation, Characterization, and Antimicrobial Activity. Ind Eng Chem Res $6 \quad 45: 2634-2640$.

7 Chou C-S, Lin S-H, Lu W-C (2009) Preparation and characterization of solid biomass 8 fuel made from rice straw and rice bran. Fuel Processing Technol 90:980-987.

9 El-Masry AM, Moustafa HY, Ahmed AI, Shaaban AF (2004a) Halamine polymers: 1. 10 Preparation and characterisation of new pyrimidinone biocidal polymers based on 11 poly-4-vinylacetophenone. Pigment Resin Technol 33:75-84.

12 El-Masry AM, Moustafa HY, Ahmed AI, Shaaban AF (2004b) Halamine polymers: 2. 13 Preparation of new triazine-diones biocidal polymers by grafting polymerisation. $14 \quad$ Pigment Resin Technol 33:211-219.

15 Garas GL, Allam ME, Ragab A (2008) Towards sustainable waste management through 16 structural testing of rice straw bale cement plasters. Waste Management and the 17 Environment IV, DOI: $10.2495 / \mathrm{WM} 080451$

18 Helmy SA, Abou-State MA (1993) Studies on the acid degradation of cellulosic fibres.

19 II. Effect of pulp characteristics on the course of degradation in hydrochloric acid20 zinc chloride solution. Polymer Degradation and stability 41:245 - 251.

21 Liu S, Sun G (2006) Durable and Regenerable Biocidal Polymers: Acyclic N-Halamine 22 Cotton Cellulose. Ind Eng Chem Res 45:6477-6482. 
1 Mansour A, Srebric J, Burley BJ (2007) Development of Straw-cement Composite

2 Sustainable Building Material for Low-cost Housing in Egypt. J Appl Sci Res 3:1571$3 \quad 1580$.

4 Miles AA, Misra SS (1938) The estimation of the bactericidal power of the blood J. $5 \quad$ Hygiene (London) 38:732-749.

6 Nada AMA, Hassan ML (2006) Ion Exchange Properties of Carboxylated Bagasse. J

$7 \quad$ Appl Polym Sci 102: 1399-1404.

8 Navaee-Ardeh S, Mohammadi-Rovshandeh J, Pourjoozi M (2004) Influence of rice straw

9 cooking conditions in the soda-ethanol-water pulping on the mechanical properties 10 of produced paper sheets. Bioresource Technol 92:65-69.

11 Prasad RDD, Reddy MR, Reddy GVN (1998) Effect of feeding baled and stacked urea 12 treated rice straw on the performance of crossbred cows. Animal Feed Sci Technol $13 \quad 73: 347-352$.

14 Sallam SMA, Nasser MEA, El-Waziry AM, Bueno CS (2007) Use of an in vitro Rumen 15 Gas Production Technique to Evaluate Some Ruminant Feedstuffs. J Appl Sci Res $16 \quad 3: 34-41$.

17 Simkovic I (1999) Preparation of anion exchangers from beech sawdust and wheat straw.

18 Industrial Crops and Products 10: 167-173

19 Sun G, Chen TY, Worley SD (1996) A novel biocidal styrenetriazinedione polymer. $20 \quad$ Polymer 37:3753-3756.

21 Suramaythangkoor T, Gheewala SH (2010) Potential alternatives of heat and power 22 technology application using rice straw in Thailand. Appl Energy 87:128-133. 
1 Toor GS, Beri V (1991) Extent of fertilizer N immobilized by the application of rice 2 straw and its availability in soil. Bioresource Technol 37:189-191.

3 Zhou J, Chang C, Zhang R, Zhang L (2007) Hydrogels Prepared from Unsubstituted

4 Cellulose in NaOH/Urea Aqueous Solution. Macromol Biosci 7: 804-809. 